\title{
Developing Methods to Evaluate Content Quality of Dementia Websites
}

\author{
Yunshu ZHUa, Ting SONG ${ }^{\mathrm{a}, \mathrm{b}}$ and Ping YUa,b,1 \\ ${ }^{a}$ Centre for Digital Transformation, School of Computing and Information \\ Technology, Faculty of Engineering and Information Sciences, \\ University of Wollongong, Wollongong, Australia \\ ${ }^{\mathrm{b}}$ Illawarra Health and Medical Research Institute, University of Wollongong
}

\begin{abstract}
With the popularity of the Internet, consumers are likely to resort to websites for dementia information. However, they may not have the knowledge or experience in distinguishing quality information from opinion pieces. This study investigated the developing methods, instruments and parameters for evaluating the content quality of dementia websites. By reviewing 18 existing instruments from the relevant literature, we identified four developing methods - questionnaire survey, automatic evaluation, Delphi method and focus group discussion. These instruments include six parameters - reliability, currency, readability, disclosure, objectivity and relevance - to evaluate the content quality. With the significant social and economic impact of dementia, developing specific instruments to measure the content quality of dementia websites is necessary.
\end{abstract}

Keywords. Health information, dementia, websites, method, evaluation, quality

\section{Introduction}

Dementia is one of the leading causes of global mortality and mortality. As it significantly impedes a person's cognition, behaviour and ability to perform daily living activities, dementia is overwhelming for patients and their caregivers, family members or paid care workers alike [1]. As there is no cure for the disease nor treatment that can alter its progression, significant investments in public campaigns and education about dementia have been undertaken by countries [2]. Although healthcare professionals are the most common and reliable source of dementia information, they are not always readily accessible. Therefore, dementia websites are also the major source of information about dementia and dementia care for the general public $[3,4]$. As a result, it has seen the booming of dementia websites all around the world.

With a substantial amount of dementia information being made available on the websites, the general public, who may not have adequate health information literacy or web search skill, to access and distinguish quality information from opinion pieces on dementia websites. Poor-quality information can lead to wrong healthcare decision making that could harm patient safety. If wrong information were used to guide dementia care, patients would suffer unnecessary distress, such as agitation. It may also negatively

${ }^{1}$ Corresponding Author, Ping Yu, Centre for Digital Transformation, School of Computing and Information Technology, Faculty of Engineering and Information Sciences, University of Wollongong, Wollongong, 2500, NSW, Australia; E-mail: ping@uow.edu.au. 
impact the physician-patient relationship [5]. In response to this significant societal need for quality dementia and dementia care information, this study addressed two questions:

- Q1. What parameters were used to evaluate the content quality of the dementia websites?

- Q2. How were these parameters evaluated, using which methods, procedures and instruments?

\section{Methods}

A scoping review was conducted by searching six databases (PubMed, PMC, CINAHL, MEDLINE, Web of Science and Scopus) with five keywords: "health" AND "method*" AND "evaluat*" AND "quality" AND "websit*" ("*" referred to a wildcard). Papers reporting the methods for evaluating the quality of health websites between 2009 and 2019 were included. All search results were exported to an Endnote library and screened by two reviewers independently. Data extracted included the measurement parameters, measurement methods, instruments and evaluation processes. For each paper, one reviewer read the full text and extracted the needed information. A second reviewer validated the data extracted to ensure reliability and validity. Disagreements were resolved by consensus [7].

\section{Results}

Twenty-one studies were reviewed [6-8,10-27]. Six parameters to evaluate the content quality of dementia websites were identified. In descending order of frequency of use, they were: reliability $(21 / 21)$ [6-8,10-27], currency $(21 / 21)$ [6-8,10-27], disclosure $(12 / 21)[10,13,15,16,18,20-24,26,27]$, readability $(11 / 21)[9-16,19,20,26]$, objectivity $(9 / 21)[6,7,10,12,16-18,20,22]$ and relevance $(6 / 21)[6,7,16,19,20,25]$ (see Table 1).

Four methods - questionnaire survey, automatic evaluation, Delphi method, and focus group discussion, were identified to develop an instrument. The questionnaire survey was the most commonly used method (18/21) [9-24,26,27]. It was independently answered by two to five health professionals/health students. The difference between the evaluations was resolved through discussion and consensus. For example, DISCERN is a brief questionnaire for health consumers to assess the quality of written information, specifically the completeness of treatment choices for a health problem. The next commonly used method is automatic evaluation $(9 / 21)$ [9-16,18], such as Flesch-Kincaid Grade Level (FKGL) and Flesch Reading Ease (FRE) Scale. When using this method to evaluate the content of a health website, a person needs to manually copy the text on the website and past it into a software application, which will automatically calculate and display the score for this text corpus according to the calculation result of a certain algorithm. Another example was HON code provided by Health On the Net Foundation [28]. It has eight principles to guide consumers to evaluate the quality of health websites (authority, complementarity, confidentiality, attribution, justifiability, transparency, financial disclosure and advertising). The Delphi method was used by Leite et al. in Portugal [7] to identify the most common parameters and their respective weights for measuring the content quality of health websites. Tao et al. [25] used focus group discussion to identify quality parameters of health websites. 
Table 1. Evaluation parameters, definition, methods and corresponding instrument of health websites.

\begin{tabular}{|c|c|c|c|}
\hline Parameter & Definition & Method & \\
\hline Reliability & $\begin{array}{l}\text { A reliable website should } \\
\text { contain references from } \\
\text { published or unpublished } \\
\text { resources }[13,17] \text {. }\end{array}$ & $\begin{array}{l}\text { 1. Focus group }[25] \\
\text { 2. Questionnaire survey } \\
{[8,16,23,25,26]} \\
\text { 3. Delphi Method }[6,7] \\
\text { 4. Automatic }[10,16,18]\end{array}$ & $\begin{array}{l}\text { 1. Interview and quality assessment } \\
{[8,25]} \\
\text { 2. DISCERN [29], Checklist [23] } \\
\text { 3. Questionnaire [6, 7] } \\
\text { 4. HONcode [28] }\end{array}$ \\
\hline Currency & $\begin{array}{l}\text { The websites should } \\
\text { include the 'create date' } \\
\text { and 'last updated' and up } \\
\text { to date [8-10]. }\end{array}$ & $\begin{array}{l}\text { 1. Questionnaire survey }[8,10- \\
\text { 12,14-19,21-24,27] } \\
\text { 2. Delphi Method [6,7] }\end{array}$ & $\begin{array}{l}\text { 1. EQIP, JAMA Benchmarks, } \\
\text { DISCERN, HRWEF [30], QCSS } \\
\text { [31], QUEST [22], DARTS [32], } \\
\text { eHealth code, Survey [8] } \\
\text { 2. Checklist } \\
\text { 3. Questionnaire }\end{array}$ \\
\hline Disclosure & $\begin{array}{l}\text { Authorship, sponsorship, } \\
\text { advertising, potential } \\
\text { conflicts of interest } \\
\text { should be fully disclosed } \\
{[9,10,20] .}\end{array}$ & $\begin{array}{l}\text { Questionnaire survey }[15,21-23 \text {, } \\
26,27] \\
\text { Automatic evaluation }[10,16,18]\end{array}$ & $\begin{array}{l}\text { 1. eHealth code [33], EQIP [26] } \\
\text { JAMA Benchmarks [34], QCSS, } \\
\text { QUEST, DARTS, Checklist } \\
\text { 2. HONcode }\end{array}$ \\
\hline Readability & $\begin{array}{l}\text { The information on the } \\
\text { websites should be clear } \\
\text { and easy to understand } \\
{[10,12,13,19] \text {. }}\end{array}$ & $\begin{array}{l}\text { 1. Focus group }[25] \\
\text { 2. Questionnaire survey }[15,26] \\
\text { 3. Delphi Method } \\
\text { 4. Automatic }[9-15,19]\end{array}$ & $\begin{array}{l}\text { 1. Interview and quality assessment } \\
\text { 2. HRWEF, eHealth code, EQIP } \\
\text { 3. Questionnaire } \\
\text { 4. FRES, FKGL, SMOG }\end{array}$ \\
\hline Objectivity & $\begin{array}{l}\text { The fact should not be } \\
\text { influenced by personal } \\
\text { feelings. The claim shoulc } \\
\text { be the whole [41]. }\end{array}$ & $\begin{array}{l}\text { tionnaire survey }[10- \\
9,21,22,24,27] \\
\text { matic }[10,16,18]\end{array}$ & $\begin{array}{l}\text { 1. DISCERN, QUEST, eHealth } \\
\text { code, Questionnaire [6] } \\
\text { 2. HONcode }\end{array}$ \\
\hline Relevance & $\begin{array}{l}\text { Content scope and } \\
\text { information support } \\
\text { should provide suite users } \\
\text { needs. }\end{array}$ & $\begin{array}{l}\text { 1. Focus group [25] } \\
\text { 2. Questionnaire survey [10- } \\
\text { 12,14-19,21,22,24, 7] } \\
\text { 3. Delphi Method [6,7] }\end{array}$ & $\begin{array}{l}\text { 1. Interview and quality assessment } \\
\text { 2. eHealth code, HRWEF, eHealth } \\
\text { code, EQIP } \\
\text { 3. Questionnaire }\end{array}$ \\
\hline \multicolumn{4}{|c|}{$\begin{array}{l}\text { eHealth code: e-Health Code of Ethics; EQIP: Ensuring Quality Information for Patients; QCSS: Quality } \\
\text { Component Scoring System; QUEST, Quality Evaluation Scoring Tool; DARTS, Author, Reference, Type and } \\
\text { Sponsor; HONcode, The Health On the Net Code; HRWEF, Health-Related Website Evaluation Form; FRES, } \\
\text { Flesch Reading Ease Score; FKGL, Flesch-Kincaid Grade Level; SMOG, Simple Measure of Gobbledygook }\end{array}$} \\
\hline
\end{tabular}

\section{Discussion}

This review identified and analysed four methods, six parameters and 18 instruments used by previous researchers in measuring the content quality of health/dementia websites. A questionnaire survey is the most commonly used one among the four evaluation methods. Among all the automatic evaluation methods, only HON providing a comprehensive assessment of the quality, and the other only assessed the readability of health websites. There is a lack of a specific automatic instrument to assess the content quality. For the Delphi method, 30 members participated in the evaluating processes with two or three rounds, including health care professionals, websites designers, university professors and students whose research is involved in the health field. This method evaluates four parameters: reliability, currency, readability, and relevance information on the websites. It is a significant method to provide a high-quality evaluation of websites, linking existing knowledge of agreement or disagreement. The focus group was only conducted in one study, providing a comprehensive assessment to the students in the health and business domain. It provides an initial step for developing criteria to evaluate health websites from consumer perspectives. However, it is only within a certain age group and lacks potential health care consumers in various backgrounds. 
The study also revealed that the instruments were generic, not specific for measuring dementia websites. In addition, these instruments used different scoring scales, such as yes/partly/no tick boxes [26] and 3- or 5- point Likert scales [10-12,14,16-19,21,24,27], making it difficult to compare the evaluation results.

This study contributes to developing nursing informatics methods. Its usefulness for nursing informatics is manifested in two aspects. First, the research topic is in the scope of nursing practice in gathering rigorous information about dementia and dementia care for own professional development and patient education. Second, the methods identified are useful to guide nurses in developing dementia and other health websites.

The limitation of this study is the inclusion of evaluation methods for the content quality of health websites. The lack of adequate studies specifically targeted the content quality of dementia websites led to the identification of two evaluation methods - Delphi and focus group discussion - as evaluation methods for dementia websites. This is not accurate as these two types of studies only developed quality parameters for the content quality of generic health websites. However, as dementia websites is a type of health website, the findings from these two types of studies are relevant.

\section{Conclusions}

This review identified six parameters for evaluating the content quality of dementia websites: reliability, currency, disclosure, readability, objectivity and relevance. Four methods were used to evaluate these quality parameters: questionnaire survey, automatic software evaluation, Delphi methods and focus group discussion. However, due to a lack of specific measurement instruments to evaluate the content quality of dementia websites, future research should focus on developing such specific measurement instruments.

\section{References}

[1] World Health Organisation. Dementia. 2019; Available from: https://www.who.int/news-room/fact sheets/detail/dementia.

[2] Prince M, Bryce R, Albanese E, Wimo A, Ribeiro W, Ferri CP. The global prevalence of dementia: A systematic review and meta-analysis. Alzheimer's \& dementia. 2013 Jan; 9(1): 63-75.

[3] Jee M, Reason L. Who cares?: Information and support for the carers of confused people. Health Education Authority. 1997.

[4] Abrahamson JA, Fisher KE, Turner AG, Durrance JC, Turner TC. Lay information mediary behavior uncovered: Exploring how nonprofessionals seek health information for themselves and others online. Journal of the Medical Library Association: JMLA. 2008 Oct; 96(4): 310.

[5] Ahmad F, Hudak PL, Bercovitz K, Hollenberg E, Levinson W. Are physicians ready for patients with Internet-based health information? Journal of medical internet research. 2006 Sep; 8(3): e22.

[6] Leite P, Gonçalves J, Teixeira P, Rocha Á. Assessment of data quality in websites: towards a model. In 2014 International Conference on Contemporary Computing and Informatics (IC3I). IEEE. 2014 Nov; 367-373.

[7] Leite P, Gonçalves J, Teixeira P, Rocha Á. A model for the evaluation of data quality in health unit websites. Health informatics journal. $2016 \mathrm{Feb}$; 22(3): 479-495.

[8] Marton C. How women with mental health conditions evaluate the quality of information on mental health web sites: A qualitative approach. Journal of Hospital Librarianship. 2010 Jan; 10(3): 235-250.

[9] Ahmed OH, Sullivan SJ, Schneiders AG, McCrory PR. Concussion information online: Evaluation of information quality, content and readability of concussion-related websites. British journal of sports medicine. 2012 June; 46(9): 675-683.

[10] Alamoudi U, Hong P. Readability and quality assessment of websites related to microtia and aural atresia. International journal of pediatric otorhinolaryngology. $2015 \mathrm{Feb}$; 79(2): 151-156. 
[11] Arts H, Lemetyinen H, Edge D. Readability and quality of online eating disorder information - Are they sufficient? A systematic review evaluating websites on anorexia nervosa using DISCERN and Flesch Readability. International Journal of Eating Disorders. 2019 Oct; 53(1).

[12] Daraz L, MacDermid JC, Wilkins S, Gibson J, Shaw L. The quality of websites addressing fibromyalgia: an assessment of quality and readability using standardised tools. BMJ. 2011;1(1): e000152.

[13] Raj S, Sharma VL, Singh AJ, Goel S. Evaluation of quality and readability of health information websites identified through India's major search engines. Advances in preventive medicine. 2016 Mar.

[14] San Giorgi MR, de Groot OS, Dikkers FG. Quality and readability assessment of websites related to recurrent respiratory papillomatosis. The Laryngoscope. 2017 Feb; 127(10): 2293-2297.

[15] Taki S, Campbell KJ, Russell CG, Elliott R, Laws R, Denney-Wilson E. Infant feeding websites and apps: A systematic assessment of quality and content. An interactive journal of medical research. 2015 Sep; 4(3): e18.

[16] Whelan AM, Jurgens TM, Bowles SK, Doyle H. Efficacy of natural health products in treating osteoporosis: What is the quality of internet patient advice? Annals of Pharmacotherapy. 2009 May; 43(5): 899-907.

[17] Fackrell K, Hoare DJ, Smith S, McCormack A, Hall DA. An evaluation of the content and quality of tinnitus information on websites preferred by General Practitioners. BMC medical informatics and decision making. 2012 July; 12(1): 70.

[18] Janssen S, Fahlbusch FB, Käsmann L, Rades D, Vordermark D. Radiotherapy for prostate cancer: DISCERN quality assessment of patient-oriented websites in 2018. BMC urology. 2019 May; 19(1): 42.

[19] Kaicker J, Debono VB, Dang W, Buckley N, Thabane L. Assessment of the quality and variability of health information on chronic pain websites using the DISCERN instrument. BMC medicine. 2010 Oct; 8(1): 59.

[20] Kashihara H, Nakayama T, Hatta T, Takahashi N, Fujita M. Evaluating the quality of website information of private-practice clinics offering cell therapies in Japan. An interactive journal of medical research. 2016 May; 5(2): e15.

[21] Prusti M, Lehtineva S, Pohjanoksa-Mäntylä M, Bell JS. The quality of online antidepressant drug information: An evaluation of English and Finnish language Web sites. Research in Social and Administrative Pharmacy. 2012 Mar; 8(3): 263-268.

[22] Robillard JM, Jun JH, Lai JA, Feng TL. The QUEST for quality online health information: Validation of a short quantitative tool. BMC medical informatics and decision making. 2018 Oct; 18(1): 87.

[23] Shahrzadi L, Mojiri S, Janatian S et al. Quality assessment of Persian mental disorders websites using the webmedqual scale. Acta Informatica Medica. 2014 Jun; 22(3): 183.

[24] Tanabe K, Fujiwara K, Ogura H, Yasuda H, Goto N, Ohtsu F. Quality of web information about palliative care on websites from the United States and Japan: Comparative evaluation study. An interactive journal of medical research. 2018 Dec; 7(1): e7.

[25] Tao D, LeRouge CM, Deckard G, De Leo G. Consumer perspectives on quality attributes in evaluating health websites. In 2012 45th Hawaii International Conference on System Sciences. IEEE. 2012 Jan; 2675-2684.

[26] Vetter D, Ruhwinkel H, Raptis DA, Bueter M. Quality assessment of information on bariatric surgery websites. Obesity surgery. 2018 Nov; 28(5): 1240-1247.

[27] Hu X, Pan H, He W, Hua H, Yan Z. Evaluation of the content quality of websites for recurrent aphthous ulcers and oral lichen planus. BMC oral health. 2017 Dec; 17(1): 170.

[28] Boyer C, Selby M, Scherrer JR, Appel RD. The health on the net code of conduct for medical and health websites. Computers in biology and medicine. 1998 Sept; 28(5): 603-610.

[29] Charnock D, Shepperd S, Needham G, Gann R. DISCERN: An instrument for judging the quality of written consumer health information on treatment choices. Journal of Epidemiology \& Community Health. 1999; 53(2): 105-111.

[30] Pealer LN, Dorman SM. Evaluating health-related Web sites. Journal of School Health. 1997 Oct; 67(6): 232-235.

[31] McGowan JJ, Passiment M, Hoffman HM. Educating medical students as competent users of health information technologies: The MSOP data. In Medinfo 2007: Proceedings of the 12th World Congress on Health (Medical) Informatics; building sustainable health systems. IOS Press. 2007 Mar; 1414.

[32] Närhi U, Pohjanoksa-Mäntylä M, Karjalainen A et al. The DARTS tool for assessing online medicines information. Pharmacy world \& science. 2008 Sept; 30(6): 898-906.

[33] Rippen H, Risk A. e-Health code of ethics. Journal of medical internet research. 2000 May; 2(2): e9.

[34] Silberg WM, Lundberg GD, Musacchio RA. Assessing, controlling, and assuring the quality of medical information on the Internet: Caveant lector et viewor-Let the reader and viewer beware. Jama. 1997 April; 277(15): 1244-1245. 